\title{
O uso de narrativas (auto)biográficas como uma possibilidade de pesquisa da prática de professores acerca da Educação (Matemática) Inclusiva
}

\section{The use of (auto)biographical narratives as a means to research the teachers' practice in Inclusive (Mathematics) Education}

\author{
Fernanda Malinosky C. da Rosa* \\ Ivete Maria Baraldi** $^{* *}$
}

\begin{abstract}
Resumo
Este artigo tem por objetivo apresentar algumas discussões sobre do uso de narrativas (auto)biográficas como fontes para a realização de pesquisas em Educação Matemática, tendo como pano de fundo considerações acerca da Educação (Matemática) Inclusiva. Ao longo do artigo, estes assuntos serão discutidos a partir de alguns trechos de memoriais de formação relacionados à pesquisa de mestrado de Rosa (2013) com a expectativa de esboçar como professores de Matemática se aproximaram da Educação (Matemática) Inclusiva e algumas de suas práticas nas classes especializadas ou inclusivas.
\end{abstract}

Palavras-Chave: Inclusão. Formação de Professores. Deficiência Visual. Memorial de Formação.

\begin{abstract}
This article aims to present some discussions about the use of (auto)biographical narratives as source to realize Mathematics Education's researches having, as background, considerations about Inclusive (Mathematics) Education. Throughout the article, these issues will be discussed from some memoir excerpts related to Rosa's (2013) master's research, expecting to outline how mathematics teachers approached the Inclusive (Mathematics) Education and some practices in specialized or inclusive classes.
\end{abstract}

Keywords: Inclusion. Teachers Education. Visual Disability. Education's Memoir.

\footnotetext{
* Doutoranda em Educação Matemática pela Universidade Estadual Paulista (UNESP), Rio Claro/SP. Endereço completo: Av. Maricá, 250, bl.16/apto.307, Alcântara, São Gonçalo/RJ. E-mail: malinosky20 @ hotmail.com ** Doutora em Educação Matemática pela Universidade Estadual Paulista (UNESP), Rio Claro/SP, . Docente do Departamento de Matemática da Faculdade de Ciências da Universidade Estadual Paulista (UNESP), Bauru/SP e docente e orientadora nos Programas de Pós-Graduação em Educação Matemática (PPGEM) da Universidade Estadual Paulista (UNESP) Rio Claro/SP e Educação para Ciências (PPGEC) da Universidade Estadual Paulista (UNESP), Bauru/SP. Endereço completo: Av. Eng. Luiz Edmundo C. Coube, 14-01, Departamento de Matemática, Bauru/SP, CEP 17033-360. E-mail: ivete.baraldi@fc.unesp.br
} 


\section{Introdução}

A narrativa autobiográfica oferece um terreno onde se pode explorar os modos como se concebe o presente, se pode ver o futuro e, sobretudo, como se conceitualizam as dimensões intuitivas, pessoais, sociais e políticas da experiência educativa. Podemos, por isso, considerar que 'os professores e pesquisadores contam histórias a seus alunos e colegas; jornalistas, romancistas e investigadores, em outras disciplinas, também contam histórias a suas respectivas audiências'. ${ }^{1}$ (BOLÍVAR; DOMINGO; FERNÁNDEZ, 2001, p.19, tradução nossa).

Ao aceitar o convite de narrar-se, o que não é fácil, enfrentamos o desafio de assumir a palavra e tornar públicas nossas lembranças, opiniões, inquietações, formações e prática profissional. Assim, a riqueza de informações presentes nas narrativas (auto)biográficas e as possibilidades de interpretações que elas promovem levam a compreender diferentes aspectos da formação docente e encadear acontecimentos relacionados à experiência profissional e, até mesmo, à vida na qual o autor é ao mesmo tempo escritor/ narrador/ personagem da história.

Para Bolívar, Domingo e Fernández (2001), “não se devia entender 'narrativa’ no sentido trivial de um texto em prosa em um conjunto cheio de enunciados, mas como um tipo especial de discurso consistente em uma narração, onde a experiência humana vivida é expressa em um relato $^{2} "$ (p. 20, tradução nossa), pois quando os educadores estão exercendo a profissão “a questão principal é tratar, articuladamente, da formação e da prática profissional porque, neste caso, quem está escrevendo o texto é um sujeito que ao mesmo tempo trabalha e está em processo de formação." (PRADO; SOLIGO, 2007, p. 56).

Essas narrativas favorecem a reflexão em relação às situações vividas pelos educadores que possam ter marcado suas escolhas, seus questionamentos ao longo de sua trajetória, as influências sofridas de âmbito pessoal, social, econômico, político, educacional etc., que possam estar presentes na formação. Prado, Ferreira e Fernandes (2011) afirmam que a reflexão não diz só sobre o cotidiano, mas também aponta a necessidade de que políticas e programas dirigidos à escola tenham eco nas vozes dos sujeitos que fazem a escola.

\footnotetext{
${ }^{1}$ La narrativa auto-biográfica ofrece un terreno donde explorar los modos como se concibe el presente, se divisa el futuro, y-sobre todo - se conceptualizan las dimensiones intuitivas, personales, sociales y políticas de la experiencia educativa. Podemos, por eso, considerar que 'los profesores e investigadores cuentan historias a alumnos y colegas; periodistas, novelistas e investigadores en otras disciplinas también cuentan historias a sus respectivas audiencias' (BOLÍVAR, DOMINGO E FERNÁNDEZ, 2001, p. 19).

${ }^{2}$ No se debía entender 'narrativa' en el sentido trivial de un texto en prosa con un conjunto enhebrado de enunciados; más bien es un tipo especial de discurso consistente en una narración, donde una experiencia humana vivida es expresada en un relato (BOLÍVAR, DOMINGO E FERNÁNDEZ, 2001, p. 20).
} 
Cabe ressaltar que utilizaremos o termo (auto)biografia com o prefixo entre parênteses, pois, além de ter um sentido mais abrangente, por incluir as biografias, autobiografias, webgrafias etc (GUSDORF, 1991 apud PASSEGGI, 2010); há, principalmente, o sentido de reflexão por parte do sujeito que narra e por se tratar de narrativas escritas em um ambiente virtual, como contaremos mais adiante.

As narrativas em questão trazem os traços das memórias que poderiam e são instrumentos de formação e podem ser considerados fontes (históricas) que trarão os traços de formação. Segundo Garnica (2003):

Narrar é contar uma história, e narrativas podem ser analisadas como um processo de atribuição de significado que permite a um ouvinte/leitor/apreciador do texto apropriarse desse texto, através de uma trama interpretativa, e tecer, por meio dele, significados que podem ser incorporados em uma rede narrativa própria. Assim, estabelece-se um processo contínuo de ouvir/ler/ver, atribuir significado, incorporar, gerar textos que são ouvidos/lidos/vistos pelo outro, que atribui a eles significados e os incorpora, gerando textos que são ouvidos/lidos/vistos... (GARNICA, 2003, p. 36).

Dessa maneira, vemos que as narrativas (auto)biográficas, repletas de vida de educadores, podem também se converter em fontes para um fazer investigativo da formação inicial e continuada e da prática dos mesmos. Entendemos prática como uma relação entre teoria e prática pedagógica, nas quais estes dois fatores são indissolúveis. Concordamos com Schmidt, Ribas e Carvalho (1998) quando dizem que: “A prática pedagógica tem como preocupação produzir mudanças qualitativas e, para isto, procura munir-se de um conhecimento crítico e aprofundado da realidade” (p. 13). Esta se caracteriza como fonte de conhecimento e geradora de novos conhecimentos; está marcada por uma opção consciente, pelo desejo de renovação, de transformação e de mudanças, pela busca e implementação de novos valores que venham a dar uma nova direção à prática social.

Ainda, as práticas profissionais geram experiências que, segundo Tardif $(2010)^{3}$, são responsáveis pelos saberes específicos baseados no trabalho cotidiano e no conhecimento do meio.

A prática cotidiana da profissão não favorece apenas o desenvolvimento de certezas 'experienciais', mas permite também uma avaliação dos outros saberes [disciplinares, curriculares e da formação profissional], através da sua retradução em função das condições limitadoras da experiência. [...] os professores tentam transformar suas relações de exterioridade com os saberes em relações de interioridade com sua própria prática. (TARDIF, 2010, p. 53-54).

\footnotetext{
${ }^{3}$ Este autor apresenta o saber experiencial (ou prático) como um dos saberes docentes.
} 
Em Tardif (2010), percebemos um sujeito que por meio da experiência adquirida faz uma reflexão sobre sua prática e julga sua formação anterior ou ao longo da carreira, métodos ou a pertinência das reformas introduzidas nos programas. Sujeito este que partilha as experiências com seus pares e, com isso, pode formar ou informar outras pessoas. Como exemplo, o autor coloca a troca de experiências de professores mais velhos com os mais jovens, o treinamento e a formação de estagiários e professores iniciantes.

É importante esclarecer que optamos por escrever Educação (Matemática) Inclusiva desta forma, porque defendemos que a prática desses professores vai além da formação matemática que tiveram, da Educação Matemática teórica ou da Educação Inclusiva que as ações governamentais preconizam. Concordamos com as pesquisadoras Fernandes e Healy (2007) quando dizem que cabe à Educação Matemática, como a todas outras áreas da Educação, estruturar-se para potencializar as competências e habilidades dos alunos com necessidades educacionais especiais, e fazer desaparecer a palavra e o conceito deficiente.

Diante do exposto, nossa intenção neste artigo é apresentar algumas discussões acerca do uso de narrativas (auto)biográficas ${ }^{4}$ como fontes para a realização de pesquisas em Educação Matemática, bem como trazer considerações acerca da Educação (Matemática) Inclusiva, a partir de trechos de narrativas de educadores que buscaram formação para trabalhar com alunos com deficiência visual em escolas inclusivas ou especializadas. Os trechos mostram como esses professores de Matemática se aproximaram da educação inclusiva, a prática profissional dos mesmos e de outros citados por eles quando o assunto é Educação (Matemática) Inclusiva. Cabe ressaltar que as práticas, aqui mencionadas, serão apontadas nos relatos dos professores, mas as mesmas não são analisadas considerando sua efetividade. Na verdade, elas aparecerão como pano de fundo para discutirmos e mostrarmos o uso das narrativas dos professores.

\section{O uso de narrativas (auto)biográficas em uma pesquisa}

Nas pesquisas na área de Educação e Educação Matemática adotam-se os memoriais como movimento de investigação-formação, seja na formação inicial ou continuada de

\footnotetext{
${ }^{4}$ Cumpre lembrar que os memoriais de formação aos quais nos referimos nesse artigo encontram-se, na íntegra, no trabalho de Rosa (2013)
} 
professores, seja em pesquisas centradas nas memórias e (auto)biografias dos mesmos (SOUZA, 2006). Mas, o que seria um memorial de formação?

Para responder a essa pergunta, buscamos fontes que nos fizessem compreender melhor esse gênero de narrativa. Passeggi (2006) traz o significado etimológico "[...] o termo memorial (séc. XIV) tem origem no latim tardio [memoriale,is] e designa 'aquilo que faz lembrar'” (p. 205, grifos da autora).

O memorial de formação, a partir dos anos 1990, tornou-se uma prática usual na formação docente. A pesquisadora Passeggi (2006) relata que, em 1994, este tipo de memorial foi adotado como dispositivo de formação de professores das séries iniciais no Curso Normal Superior, no Rio Grande do Norte, a fim de promover atitudes reflexivas antes e depois da graduação. Hoje, a defesa do memorial é adotada como requisito para finalização da graduação em alguns cursos de universidades como, por exemplo, na Universidade Federal do Rio Grande do Norte.

Segundo Sartori (2008), o memorial de formação é também utilizado para a obtenção do diploma de graduação no curso de Pedagogia na Universidade Estadual de Campinas (UNICAMP), mais especificamente, no PROESF (Programa Especial para Formação de Professores em Exercício na Rede de Educação Infantil e Primeiras Séries do Ensino Fundamental da Rede Municipal dos Municípios da Região Metropolitana de Campinas).

Os pesquisadores Prado e Soligo (2007) defendem que a produção de textos escritos favorece o pensamento reflexivo, o que é uma ferramenta valiosa na formação. Para eles, o memorial de formação é um gênero textual privilegiado "para que os educadores - enfrentando o desafio de assumir a palavra e tornar públicas as suas opiniões, as suas inquietações, as suas experiências e as suas memórias - escrevam sobre o processo de formação e a prática profissional" (p. 46). E continuam falando que:

Sendo o memorial de formação, já se tem aí ao mesmo tempo uma explicação e um fator limitante: o conteúdo, em linhas gerais, é nossa formação e, mais, nossas experiências e partes da história de vida que se relacionam em essas duas dimensões. Mesmo que se opte por um texto mais livre, ainda assim estará referenciado no fato de que se trata de um memorial que é de formação.

Nessa perspectiva, pode-se trazer elementos da formação humana que 'entram' na formação profissional: as reflexões que tiveram lugar a partir do curso do qual se participa/participou - e as mudanças decorrentes - representam os pontos mais significativos a serem abordados. É importante explicitar a relação entre formação humana e profissional e, estando já na profissão, o que contribui para as transformações que forem acontecendo. (PRADO; SOLIGO, 2007, p. 56). 
Larrosa (2006) defende a produção de narrativas ou relatos de formação para ser utilizada na formação inicial ou continuada: "Produzimos as histórias que depois tratamos com diferentes ferramentas metodológicas e para distintas finalidades. Contribuímos na elaboração das histórias que depois vamos colocar em cena nos diferentes contextos teóricos e práticos." (p. 185).

As pesquisadoras Teixeira et al (2010) ressaltam a riqueza das informações presentes nas narrativas e as possibilidades de interpretações que elas suscitam, o que propicia a compreensão de diferentes aspectos da formação docente, tais como:

[...] a ideia de formação do professor como um processo permanente, sempre inconcluso e que requer aprendizagens sobre a profissão e também sobre si mesmo obtidas ao longo de toda a sua história de vida, no ambiente familiar, como aluno da educação básica, nos cursos de formação específica para o magistério, bem como na reflexão exigida pelos desafios da experiência prática (TEIXEIRA et al, 2010, p. 122).

Referente ao processo de escrita dos memoriais, Passeggi (2006) diz que "a escrita do memorial é simbolizada, inicialmente, como 'luta', em seguida, como 'ato de conceber' e, finalmente, como "viagem"” (p. 210-211). A mesma autora ainda fala da dificuldade em escrever quando o ambiente é institucional:

Simbolicamente, a escrita do memorial seria experienciada através de duas visões paralelas: a de luta e a de luto. Uma luta que se trava contra as dificuldades da escrita e os demônios interiores. Um luto pela morte de si mesmo, com um outro, para renascer sob uma nova forma (PASSEGGI, 2006, p. 211).

Os educadores que assumem o compromisso da escrita declaram que um pouco de sonho e de utopia "sempre pode se tornar realidade quando os problemas são encarados e, ao invés de nos paralisarem, mobilizam a ação, alimentam a reflexão, dão sentido ao movimento de açãoreflexão-ação" (PRADO; FERREIRA; FERNANDES, 2011, p. 146). Os pesquisadores comentam ainda que, com essa escrita, profissionais fazem "um bonito retrato do exercício do direito de inventar inéditos, de inventar a si, de inventar a nós mesmos" (Ibidem).

Nessa perspectiva, a escrita deste tipo de narrativa é explorada em um movimento de investigação-formação, uma abordagem (auto)biográfica, que focaliza o processo de conhecimento e de formação que se articula ao exercício da tomada de consciência, por parte do sujeito, das aprendizagens ao longo da vida, as quais são expressas pela metarreflexão do ato de narrar sobre si mesmo (NAKAYAMA, FIORENTINI, BARBOSA, 2010).

Assim, a abordagem (auto)biográfica das trajetórias de escolarização e formação, dos memoriais de formação, inscreve-se em uma abordagem epistemológica e metodológica, por compreendê-la como processo (auto)formativo, por meio das experiências dos atores em 
formação e por possibilitar a ampliação da compreensão do mundo escolar e de práticas culturais do cotidiano dos sujeitos em processo de formação (SOUZA, 2006).

O memorial favorece a reflexão em relação às situações vividas pelos professores que possam ter marcado suas escolhas, seus questionamentos ao longo de sua trajetória, as influências sofridas de âmbito pessoal, social, econômico, político, educacional etc., que possam estar presentes na formação.

Em Rosa (2013), o objetivo era o de esboçar uma compreensão de como professores de Matemática, em seu processo de formação, se aproximam da educação inclusiva de alunos com deficiência visual e de como percebem a Educação (Matemática) Inclusiva. Nessa pesquisa, as narrativas (auto)biográficas foram, em específico, os memoriais de formação dos professores de Matemática, as fontes principais para que o objetivo fosse alcançado. Dessa maneira, nos atrevemos a adotar os memoriais com a intenção primeira de explorar as potencialidades de um instrumento de formação e metodológico de pesquisa. Como na maioria dos trabalhos desenvolvidos pelo Grupo História Oral e Educação Matemática (GHOEM) ${ }^{5}$, do qual fazemos parte, são utilizadas narrativas (orais), os memoriais de formação se apresentam como uma possibilidade de continuar usando as narrativas de professores, agora escritas.

Escolhemos o memorial de formação e não outro tipo de narrativa (auto)biográfica, por entendermos que ele permite o narrar a partir das frases disparadoras, com a intenção de pesquisa, como também favorece a reflexão, o que é possível perceber na leitura de cada um dos memoriais e do "questionário" chamado Sensações pós-memorial 6 , que foi respondido pelos professores após a escrita. Este gênero textual propicia a formação que, neste caso, compreendemos como sendo um ciclo, o professor sempre está em formação, esta não acaba na graduação ou em cursos de formação continuada.

\footnotetext{
${ }^{5}$ Esse estudo não é uma pesquisa histórica, contudo fornece novos elementos para um projeto maior denominado "Mapeamento da Formação e Atuação de Professores de Matemática no Brasil" desenvolvido pelo GHOEM projeto este que visa realizar um entendimento da formação de professores de Matemática das distintas regiões que compõem o Brasil, ao trazer considerações acerca da formação de professores (de Matemática) do Rio de Janeiro quando relacionados à educação inclusiva.

${ }^{6}$ A ideia das Sensações pós-memorial surgiu depois que a primeira autora deste artigo escreveu seu memorial de formação. Após perceber que durante a escrita vão surgindo inúmeras lembranças e sentimentos, todos ao mesmo tempo, de um jeito que não dá para saber por onde começar, o que contar. Cada lembrança remete a um sentimento diferente, que pode não ser o sentimento que tivemos quando o narrado ocorreu. E todos nós estamos (re)lendo, (re)observando lembranças e esta ação, geralmente, traz a reflexão consigo. Para tentar entender como foi essa escrita para os outros professores e, ao mesmo tempo, apontar como poderíamos olhar/perceber a reflexão e a formação, foi criado o "questionário" Sensações pós-memorial.
} 
$\mathrm{Na}$ pesquisa de Rosa (2013), os colaboradores foram professores de Matemática, que participaram do curso Braille online - Módulo Básico oferecido pela Universidade Federal Fluminense (UFF), localizada em Niterói/ RJ. O curso ministrado pela primeira autora foi realizado no segundo semestre de 2011, na modalidade semipresencial via plataforma Moodle. Nesta plataforma, além de discussões sobre leis vigentes e educação inclusiva, também ficou disponível o material do curso (vídeos, textos, entre outros) para que os participantes pudessem cumprir as tarefas avaliativas de acordo com o cronograma fechado pela coordenação.

Os participantes eram, em sua maioria, licenciandos da UFF e professores em exercício que buscavam um meio de aprender a lidar com os alunos cegos que estavam inseridos em suas salas de aula. Nossa primeira intenção era a de produzir os memoriais com os colaboradores durante o curso de braille oferecido pela UFF no ano seguinte, no entanto, isso não foi possível, pois não abriram inscrições para 2012.

Assim, decidimos atuar junto aos professores já formados naquele curso de 2011, visando olhar para sua formação, observando como eles se aproximaram e perceberam o movimento de educação inclusiva de alunos com deficiência visual nas escolas regulares. O convite aos colaboradores, que foram tutores ou alunos do curso de braille, foi realizado por e-mail. Aos que aceitaram, foi agendada uma reunião presencial.

No que se refere à construção dos memoriais, foi criado um blog: www.narrativasdeprofessores.com.br/jcow, nosso diário virtual, cuja finalidade não era só de manter o contato e direcionar os docentes colaboradores, mas também de compartilhar lembranças, ideias e dúvidas acerca do que estava sendo produzido. O referido blog era muito parecido com uma rede social bastante utilizada pelos participantes, então a intenção era levar os professores para sua zona de conforto, estimulando-os assim à escrita de sua vida pessoal. Escolhemos este meio por acreditarmos que ele seja mais dinâmico, no qual a distância física é reduzida, além da proximidade entre a fala e a escrita. Um espaço que mesmo tendo por base a escrita, a oralidade está presente.

Para estimular tal escrita, utilizamos cinco frases disparadoras que abordavam temas como: as escolas da infância e adolescência, a universidade, a Matemática, a profissão, os cursos de formação continuada e a educação inclusiva. Após dissertarem a partir das cinco frases, os relatos foram reunidos na ordem em que foram escritos e constituíram o memorial de formação do participante. Cada um revisou e legitimou seu memorial com uma carta de cessão. 
A seguir apresentaremos trechos de quatro dos dez memoriais presentes na dissertação de Rosa (2013), os quais julgamos que mostram a prática em sala de aula em escolas especializadas ou regulares inclusivas desses professores de Matemática, bem como os mesmos se aproximaram da Educação (Matemática) Inclusiva.

\section{Alguns trechos de memoriais e considerações sobre Educação (Matemática) Inclusiva}

Para este artigo, selecionamos trechos de quatro memoriais: Paula e Heverton que trabalham em uma escola especializada e Pablo e Viviane, formados há três anos, que trabalham em escolas regulares inclusivas ${ }^{7}$.

A professora Paula, que atualmente é professora de Matemática aposentada e trabalha capacitando professores para atuarem com alunos com deficiência visual, conta em seu memorial sua prática como professora e como formadora. Paula faz parte do grupo "Educação Matemática para Deficientes Visuais" do Projeto Fundão, da Universidade Federal do Rio de Janeiro (UFRJ), que faz estudos e cria materiais adaptados para um melhor entendimento da disciplina e adapta livros didáticos de Matemática. Ao mesmo tempo que Paula usa esses materiais em classes do Ensino Fundamental da escola especializada, ela ensina a outros professores como construí-los e adaptá-los. Ela, a partir de sua vivência como formadora, aponta as práticas dos demais professores que encontrou na escola inclusiva ou no curso de formação:

Eu conversava e discutia com professores; alguns não aceitavam dar aula para cegos, enquanto outros faziam desenhos em relevo nas tampas de alumínio de leite em pó. Às vezes o ano letivo já tinha começado e muitos professores nem sabiam quais eram os seus alunos. [...] Um dos relatos que me recordo: um professor de inglês [...] estava dando aula e fez uma pergunta para a turma. Ele olhou na sala e falou: 'Você que está dormindo não ouviu a minha pergunta, não é?' E o aluno respondeu: 'Professor, eu ouvi e posso responder, apenas sou cego'. O professor ficou super sem graça e depois da aula pediu desculpas para o aluno (excerto do memorial de Paula ROSA, 2013, p. 188).

Isso mostra por um lado a aceitação (ou não) dos professores que estão recebendo alunos incluídos e uma concepção ou rótulo que algumas pessoas atribuem às pessoas cegas.

\footnotetext{
${ }^{7}$ Estamos chamando de escolas inclusivas aquelas que recebem alunos com alguma deficiência. No entanto, talvez coubesse uma discussão sobre a escola que hoje temos. Entendendo que não seria possível nesse artigo, indicamos o trabalho de Rosa (2014) que apresenta considerações sobre se a escola que temos é inclusiva.
} 
Com a criação e o uso de materiais adaptados para facilitar o ensino de geometria e com sua participação no Projeto Fundão, ela conta que teve a oportunidade de se apresentar em muitos congressos nacionais e internacionais.

Por meio da narrativa de Paula podemos pensar que a aproximação dela com a educação de alunos com deficiência visual aconteceu após ter sido contratada por uma escola especializada e, talvez mais fortemente, quando fez o curso de especialização e começou a lecionar em uma classe do $4^{\circ}$ ano do Ensino Fundamental, mesmo sendo formada para lecionar a partir do $6^{\circ}$ ano. A aproximação de Paula com a Educação (Matemática) Inclusiva acontece ao capacitar outros professores para trabalhar com alunos com deficiência visual nas escolas regulares e ao criar e adaptar maneiras/atividades que facilitem o ensino de professores de Matemática e a aprendizagem destes alunos.

Em relação à prática docente, Paula relata sobre a criação e adaptação de materiais didáticos, sobre os quais veremos melhor a importância a seguir, e aponta questões como a aceitação dos professores no que diz respeito à inserção de alunos com deficiência visual nas escolas inclusivas. Ela, que já participou de um convênio entre a escola especializada que trabalhava e uma escola inclusiva (capacitava professores de Matemática desta última escola e adaptava provas e trabalhos para a escrita em braille), aponta a (não) aceitação por parte de alguns professores da política de inclusão (im)posta pelas leis que não foi (nem vem sendo) acompanhada na mesma velocidade pelos cursos de formação de professores. Concordamos com Glat e Nogueira (2002) quando dizem que:

Inúmeras são as barreiras que impedem que a política de inclusão se torne realidade na prática cotidiana de nossas escolas. Entre estas, a principal, sem dúvida, é o despreparo dos professores do ensino regular para receber em suas salas de aula, geralmente repletas de alunos com problemas de disciplina e aprendizagem. (GLAT; NOGUEIRA, 2002, p. 22)

Não podemos creditar a responsabilidade da implantação e sucesso da educação inclusiva somente aos docentes, como também não podemos atribuir ao aluno exclusivamente a responsabilidade por suas dificuldades, e não se pode designar exclusivamente à escola a responsabilidade pelos obstáculos que vem encontrando (KAFROUNI; PAN, 2001). É preciso admitir que a escola e seus membros, frente à situação iniciada na Declaração de Salamanca (BRASIL, 1994) e demais leis como o atual Plano Nacional de Educação - Meta 4 (BRASIL, 2014), também têm suas "necessidades educacionais especiais", pois as escolas precisam "aprender" a lidar com uma nova demanda. 
Heverton, em sua narrativa, conta suas lembranças como aluno com baixa visão que estudava em uma escola especializada, mostrando como foram as práticas de seus professores:

Nas aulas de Geometria, a professora fazia apostilas. Nas apostilas em Braille, ela fazia os desenhos em alto relevo para os alunos cegos. Ela fazia a apostila em um papel que é tipo uma folha de plástico, chamado braillon ${ }^{8}$ Hoje, já temos recursos para fazer desenhos e imprimir em papel estes desenhos. [...] Em determinado momento, a professora nos propôs ensinar Desenho Geométrico com material adaptado. (excerto da narrativa de Heverton - ROSA, 2013, p. 193194).

Ainda em suas lembranças como aluno de uma escola inclusiva, em um segundo momento, Heverton conta que o professor o enxergava como qualquer outro aluno da turma, o que por um lado era bom porque não tinha uma diferenciação, mas por outro, o professor não apresentava recursos para facilitar seu enxergar do quadro e também não ditava a matéria. Com isso, o aluno com deficiência visual tinha que tirar cópia da matéria ou pedir para os outros alunos copiar com um papel carbono, o que deixava o caderno do colega marcado de tinta. Quando tinha matéria que o professor dava em sala que, antes de terminar a aula, ele ia usar ou ler, ele ficava sem ter o que fazer. Isso tudo o motivou a encontrar uma maneira de enxergar o quadro. À época, ele não tinha como comprar um monóculo e teve a ideia de usar um binóculo em sala de aula, mesmo sentindo vergonha dos colegas.

No decorrer do ano, senti dificuldade em não enxergar o quadro, pois os professores não estão muito acostumados em falar o que realmente estava no quadro. Na hora da explicação, principalmente em Matemática, era mais ou menos assim, 'vocês vão pegar isso aqui (apontando ou sublinhando com o giz), colocar ali e depois volta para cá'. Para quem não enxerga o quadro, já era! Não entendia nada! Então, lá ia eu, levantava o dedo antes dele terminar a explicação. $O$ professor falava: 'deixa eu terminar'. Quando ele terminava, eu pedia para ele repetir, só que ao invés de apontar, dizer aqui, ali, etc, pedia para descrever. Assim, comecei a pensar em alguma coisa para enxergar o quadro. (excerto da narrativa de Heverton - ROSA, 2013, p. 196).

Agora como aluno de uma universidade, cursando licenciatura em Matemática, Heverton conta da dificuldade em enxergar o quadro e aparecer na sala de aula com um binóculo, do seu êxito nas disciplinas de Cálculo e Estatística, por exemplo, e da atitude de alguns professores quando a disciplina exigia um pouco mais da sua visão:

No segundo período da faculdade, tive problemas na disciplina de Construção Geométrica, devido a minha visão não conseguia fazer os desenhos com precisão, mas sabia toda a técnica na construção. Só que errando um centímetro aqui, outro centímetro ali, nunca consegui traçar um desenho apropriado para o que era exigido pela disciplina. Tentava conversar com a professora, mas ela não dava menor sinal de compreensão. Com toda esta situação fiquei reprovado. Nos

\footnotetext{
${ }^{8} \mathrm{O}$ braillon é uma película plástica que, utilizado em uma máquina térmica de pressão denominada Thermoform, faz a duplicação permanente, em alto relevo, do braille e de desenhos como, por exemplo, mapas táteis.
} 
períodos seguintes, busquei outros professores que davam esta disciplina em outros campi e conversei com um deles falando sobre a minha dificuldade nos desenhos precisos. Ele disse que me avaliaria pelo conceito, eu teria que fazer os desenhos e explicar toda a teoria. Deu tudo certo. Consegui dar mais um passo que parecia estar travado (excerto da narrativa de HevertonROSA, 2013, p. 197).

Em um segundo momento, Heverton conta sobre sua prática como professor de Matemática em uma classe somente com alunos com deficiência visual. Ele é colega de trabalho da professora Paula e, em sua narrativa, ressalta que também participou do Projeto Fundão por algum tempo. Neste trecho, ele mostra como fez para explicar o conceito de ângulo para alunos com deficiência visual:

Sinto que tenho que melhorar muito, mas a professora Paula sempre me dá muita força e grandes ideias para que eu possa melhorar. Principalmente, quando não consigo realizar determinadas atividades ou explicar determinado conteúdo como, por exemplo, tentei explicar aos alunos o conceito de ângulo, mas percebi que eles não compreenderam bem, então "me deu estalo", tive a ideia de pegar um transferidor daqueles de madeira grandão que o professor usa em sala de aula e pedi para uma pessoa do setor de marcenaria fazer umas marcações a cada cinco graus. Eu queria trabalhar com eles da seguinte forma: cada aluno representa um ponto e, com um barbante, eles formem o ângulo, a medição será feita com o transferidor adaptado. Tentei usar um transferidor de plástico com umas marcações em plástico autoadesivo, mas os alunos não conseguiram perceber direito as marcações (excerto da narrativa de Heverton - ROSA, 2013, p. 199).

Na narrativa de Heverton, hoje como professor da escola especializada, percebemos que ele relata os tempos de estudante no qual ele passou por esta mesma escola em que trabalha e, ao término do Ensino Fundamental, foi para uma escola inclusiva. Os conhecimentos que ele obteve foram na prática porque, conforme o relato, tanto o colégio quanto a universidade, na qual cursava licenciatura em Matemática, não tinham um preparo, pelo contrário, parece que aprenderam ou tentaram se adaptar por ter um aluno com uma limitação visual.

Essa narrativa é bastante interessante e importante para percebermos que não é por ele ter esta limitação que seria natural ou mais fácil se aproximar das questões relativas à Educação (Matemática) Inclusiva. Percebemos que, primeiramente, ele teve que amadurecer as ideias quanto a sua escolha profissional e atuar como professor de Matemática para, então, se sensibilizar para encontrar uma solução viável para as mesmas dificuldades que enfrentou enquanto aluno. Muitas vezes, quando estamos imersos numa determinada situação, fica difícil percebemos pelo que devemos lutar; entendemos que ao sofrermos diariamente exclusões, isso não nos habilita, automaticamente, a entendermos o que seja uma educação inclusiva. 
Sobre a prática do professor Heverton para incluir os alunos cegos nas aulas de Matemática, podemos dizer que vai além de uma política de Educação Inclusiva e das recomendações contidas nas leis vigentes, é um compromisso profissional com seus alunos. Nos trechos de memorial, observamos a participação da professora Paula em sua formação e percebemos não só a importância da adaptação de materiais para o ensino da Matemática, mas principalmente os conceitos que necessitam do auxílio da visão para serem melhor compreendidos, como o exemplo do conceito de ângulo. Observamos, também, a importância da adaptação da linguagem usada em sala de aula e/ou para explicar um conteúdo. As dificuldades que Heverton teve enquanto aluno, ele tenta minimizar enquanto professor, criando materiais didáticos para facilitar o ensino de Matemática para alunos cegos e com baixa visão. Outra questão que aponta é a importância da adaptação do currículo ao relatar sobre sua dificuldade na disciplina "Construções Geométricas", por causa da pouca visão e da posição dos professores da faculdade frente a isso.

A professora Viviane conta em sua narrativa que, à época da graduação, cursou disciplinas voltadas para o tema inclusão na Faculdade de Educação, foi monitora das disciplinas de "Construções Geométricas" e "Fundamentos de Geometria", foi bolsista de extensão do projeto "Vendo com as mãos" do Laboratório de Ensino de Geometria (LEG) da Universidade Federal Fluminense (UFF), quando também começou a fazer estágio obrigatório em uma escola inclusiva. Além disso, foi tutora presencial do curso de Braille quando já tinha terminado a graduação.

A educação inclusiva é descrita, em seu memorial, como sendo "Um caminho para a diversidade" e diz que a maioria dos professores que é contra a educação inclusiva é composta por aqueles que não se importam com os alunos, entram em suas salas de aula sem se questionarem sobre sua responsabilidade social. Observou que em algumas escolas, quando existe um aluno com alguma deficiência, eles são "colocados de lado", pois boa parte dos professores não sabe lidar com esses alunos ou, simplesmente, não querem ajudá-los.

Assim, entendemos que Viviane percebe a educação inclusiva como uma responsabilidade social e um caminho para a diversidade, criticando a atitude de professores que promovem a "exclusão" de seus alunos. A pesquisadora Mrech (1999) aponta uma possível mudança dos professores: 
Para que tudo isso se modifique, não basta apenas nós trabalharmos com os conteúdos cognitivos no processo de formação dos educadores. Pois, se eles não quiserem mudar, se eles não tiverem desejo de saber instaurado, por mais conteúdos que nós possamos lhes dar, eles permanecerão da mesma forma. Depende do desejo do professor, assim como do desejo do aluno, fazer ou não essa mudança. O poder das políticas públicas encontra o seu limite maior no desejo dos sujeitos. Se eles não quiserem mudar as suas práticas estigmatizadoras, eles não mudarão (MRECH, 1999, p. 137).

Em relação à prática, Viviane ainda não teve um aluno com deficiência visual nas escolas em que é professora, mas acredita que esteja preparada para ministrar aulas a estes estudantes, pois, durante a graduação, conviveu com alunos com deficiência e desenvolveu atividades que estimulam o ensino e a aprendizagem de Matemática, participou de projetos de criação de materiais didáticos e buscou uma melhor preparação para ministrar aulas em classes inclusivas. Ainda, apresenta por fotos o conjunto de artefatos e atividades que criou e adaptou para introduzir os conceitos básicos da geometria euclidiana plana e os cinco Axiomas de Euclides: “[...] criei e adaptei um conjunto de artefatos e atividades que introduz os conceitos básicos da geometria euclidiana plana e os 5 Axiomas de Euclides. Os artefatos são todos confeccionados com materiais de baixo custo" (excerto da narrativa de Viviane - ROSA, 2013, p. 205).

O professor Pablo, como Viviane, buscou disciplinas sobre o tema na época da graduação. Ele conta que cursou a disciplina optativa "Tópicos Especiais em Educação Especial” e participou do evento "Escola de Inclusão", ambos oferecidos pela Faculdade de Educação da UFF. Quando cursou a disciplina "Laboratório de Educação Matemática", ministrada pela professora Ana Kaleff que também coordena o LEG, ele teve a oportunidade de participar de um projeto de extensão que criava e levava materiais didáticos para aplicação em uma escola especializada. Pablo, em sua narrativa, diz que:

Observando a prática escolar, eu suponho que, em geral, uma aula puramente expositiva e padronizada não é suficiente para alcançar a diversidade de alunos, e mais precisamente, a diversificação de compreensão dos alunos. Em particular, no caso de alunos com deficiência visual, uma aula preparada com recursos que dependa decisivamente da visão, tem poucas chances de alcançar este grupo de alunos. É necessário pensar em propostas que levem os alunos a uma melhor compreensão dos objetos matemáticos, principalmente os alunos com necessidades educacionais especiais (excerto da narrativa de Pablo - ROSA, 2013, p. 209-210).

Destaca que a educação inclusiva é uma "prática escolar" e, em sua opinião, abrir as portas da escola para alunos com deficiência não é sinônimo de educação inclusiva, há a necessidade de aulas adequadas, propostas que levem os alunos a uma melhor compreensão da Matemática, em particular. Ele crê que o professor deve sair melhor preparado para trabalhar com 
a nova demanda de alunos e este deve sempre se especializar. Segundo o mesmo, não se deve esperar uma intervenção governamental, pois esta será demorada: "o professor precisa se mobilizar para transformar o seu ambiente escolar num ambiente mais inclusivo (inclusivo no sentido mais amplo da palavra)" (excerto da narrativa de Pablo, ROSA, 2013, p. 210).

Sobre a aproximação de Pablo em relação à educação inclusiva, ao ler o memorial por completo, isso nos pareceu ocorrer antes dele ter consciência do que seria isso. Por curiosidade ou já por afinidade, interessava-se em interagir com pessoas com deficiência intelectual de sua antiga escola. Talvez, não tenha sido isso que o levou a trilhar esse caminho de formação. $\mathrm{Na}$ universidade, mesmo sendo bolsista e participando de cursos voltados para o bacharelado em Matemática, buscou disciplinas e cursos optativos oferecidos pela Faculdade de Educação da UFF que eram especificamente sobre educação inclusiva.

Nesses trechos de memoriais percebemos que os professores estão preocupados quanto à sua formação e à preparação, buscando disciplinas e cursos que os preparem melhor para educar alunos com diversos tipos de deficiência. Ainda, os professores contam suas práticas escolares com intuito de favorecer a aprendizagem da Matemática pelo aluno com deficiência visual, baseados em vivências em grupos ou disciplinas que exploraram a criação de materiais didáticos adaptados. No caso da professora Paula, após trabalhar muitos anos em classes de educação de cegos e de alunos com baixa visão, mostra um outro lado que é o da formação de docentes e conta que alguns não aceitam a inclusão.

Os memoriais, em questão, trazem os traços das memórias que poderiam e são instrumentos de formação e com eles foi possível também observar a prática de alguns dos professores de Matemática em suas salas de aula, sejam elas especializadas ou regulares inclusivas.

\section{Considerações finais}

A partir das narrativas é possível refletir não só sobre como os professores de Matemática percebem e se aproximam da Educação Inclusiva, mas também como foram (ou são) suas experiências e práticas. Em Rosa (2013), tivemos algumas compreensões sobre o uso de memoriais como fonte histórica e do blog como uma ferramenta para captar a oralidade na contemporaneidade. Os relatos presentes nos memoriais de formação trazem não só lembranças 
como, também, o tempo vivido pelo narrador, que passa a ser o presente do passado. Esse tempo da narrativa pode ser tanto um tempo cronológico enquadrado pelo tempo do calendário, quantificado pelo relógio, incorruptível, denominado tempo Chronos, como pode ser um tempo caótico, exigente e subversivo, o da memória, denominado tempo Kairos, ou ainda, um misto dos dois (FERNANDES; GARNICA, 2012).

Fernandes e Garnica (2012) dizem ainda que "se a História ordena, encadeia, lineariza, objetiva, continua; a memória filtra, reordena, dá trelas aos desejos humanos, reescreve, fantasia, trata de uma continuidade descontinuada, cravada de abismos e vagos espaços” (p. 175). Essas lembranças são de um passado visto pelo presente, olhares pessoais, individuais, por isso os relatos não são necessariamente sequenciais e lineares. Com isso e dada a natureza seletiva e subjetivada memória, o narrado pode ser ressignificado no ato da escrita.

Dessa maneira, vemos que os memoriais, repletos de vida de professores, podem também se converter em fontes para um fazer investigativo da formação inicial e continuada. Estas narrativas permitiram lançar o olhar sobre esse professor, tentando, assim, entender suas buscas, suas opiniões, seus sentimentos, suas participações neste processo.

A partir dos trechos de memoriais que destacamos, mostramos a aproximação dos professores com projetos relacionados à criação de materiais adaptados para o ensino de Matemática, bem como à confecção destes para a aplicação em sua prática docente.

Segundo algumas leis que recomendam a Educação Inclusiva (BRASIL, 2001a, 2001b, 2008), é primordial que o currículo escolar seja adaptado para que os alunos com necessidades educativas especiais possam aprender Matemática de maneira significativa, e, sobretudo, os alunos cegos necessitam de recursos didáticos táteis, para que possam auxiliar em sua construção do conceito, neste caso, matemático. Barbosa ressalta que:

Utilizando bom senso e criatividade, o professor pode selecionar, adaptar e confeccionar materiais didático-pedagógicos que contribuam para o processo ensino-aprendizagem de todos os alunos. A escolha deve basear-se, de um modo geral, nos princípios de que os materiais mais adequados são aqueles que permitem uma experiência completa ao aluno e estão compatíveis com o seu nível de desenvolvimento (BARBOSA, 2003, p. 19).

Cerqueira e Ferreira (1996) afirmam que, provavelmente, "em nenhuma outra forma de educação os recursos didáticos assumam tanta importância como na educação especial de pessoas deficientes visuais" (p. 1). Os autores levam em conta, entre outros, os seguintes aspectos: a dificuldade de contato da pessoa com deficiência visual com o ambiente físico e a carência de material adequado, o que pode conduzi-lo a um formalismo desvinculado da realidade. 
Quanto aos recursos didáticos que podem ser utilizados nas aulas de Matemática, especificamente com alunos cegos, a maioria dos professores, em seus memoriais, cita conhecer alguns destes recursos, bem como a importância em utilizá-los. No entanto, o professor Heverton detalha alguns materiais que utiliza e diz que tem dificuldades em explicar alguns conteúdos, pois o aluno com baixa visão possui um conhecimento visual maior que o cego, implicando em maneiras diferentes de adaptar o ensino de conceitos matemáticos, muitas vezes, em uma mesma sala de aula.

As ações dos projetos da UFRJ e UFF, citados pelos participantes, vão além da questão da adaptação recomendada pelo Ministério da Educação para alunos com deficiência visual, que dispõe sobre a criação de condições físicas, ambientais e materiais para o aluno, como posicionar o mobiliário para facilitar a locomoção, descrever todo o material usado em sala de aula, oferecer suporte físico, verbal e instrucional no que se refere à orientação e mobilidade e disponibilizar recursos materiais como pranchas, lupa, material didático ampliado, livro falado, equipamento de informática etc. Essas ações contribuem no processo de ensino e aprendizagem, auxiliando na abstração da Matemática e os materiais têm a possibilidade de ajudar alunos com ou sem necessidades educacionais, dependendo da adaptação que necessitem.

Percebemos que os professores, participantes de nossa pesquisa, têm uma prática diferenciada e são sensíveis à necessidade de usar materiais adaptados nas aulas de Matemática, principalmente, com alunos com deficiência visual. No entanto, talvez essa não seja a prática de grande parte do corpo docente das escolas básicas, tanto do Rio de Janeiro quanto do Brasil.

Por fim, essa foi nossa maneira para contribuir com as discussões sobre o uso de narrativas (auto)biográficas em pesquisas sobre a prática de professores em Educação (Matemática) Inclusiva.

\section{Referências}

BARBOSA, P. M. O Estudo da Geometria. Revista Benjamin Constant, Rio de Janeiro, n. 25, p. 14-22, agosto, 2003.

BOLÍVAR, A.; DOMINGO, J.; FERNANDEZ, M.. La investigación biográfico-narrativa en educación: enfoque y metodología. Madri, Espanha: Editorial La Muralla S.A., 2001.

BRASIL. Coordenadoria Nacional Para Integração da Pessoa Portadora de Deficiência Declaração de Salamanca e Linha de Ação sobre necessidades Educativas Especiais. Brasília: MAS/CORDE, 1994. 
BRASIL. Conselho Nacional de Educação. Resolução n 2/2001 de 11 de setembro de 2001. Brasília, DF: CNE/CEB, 2001 a.

BRASIL. Conselho Nacional de Educação. Parecer n ${ }^{\circ}$ 17/2001 de 3 de julho de 2001. Brasília, DF: $\mathrm{CNE} / \mathrm{CEB}, 2001 \mathrm{~b}$.

BRASIL. Secretaria de Educação Especial. Política Nacional de Educação Especial na Perspectiva da Educação Inclusiva. Brasília: MEC, 2008.

BRASIL. Secretaria de Articulação com os Sistemas de Ensino. Plano Nacional de Educação (PNE). Brasília: MEC/SASE, 2014.

CERQUEIRA, J. B.; FERREIRA, E. de M. B. Recursos Didáticos na Educação Especial. Revista Benjamin Constant, Rio de Janeiro, n. 5, p. 24-29, dezembro, 1996.

FERNANDES, D. N.; GARNICA, A.V. M.. Temporalidades Distintas: um estudo sobre a formação de professores de matemática no Maranhão. In: FERREIRA, A.C.F.; BRITO, A.J.; MIORIM, M.A.(Orgs). Histórias de Formação de Professores que Ensinaram Matemática no Brasil. 1 ed. Campinas: Ilion, 2012, v. 1, p. 175-189.

FERNANDES, S.H.A.A.; HEALY, L. Ensaio sobre a inclusão na Educação Matemática. Revista Iberoamericana de Educación Matemática, La Laguna (Tenerife), v. 10, p. 59-76, junho, 2007.

GARNICA, A.V. M.. História Oral e Educação Matemática: do inventário à regulação. Zetetiké, Campinas, v.11, n. 19, p. 9-55, Jan./Jun., 2003.

GLAT, R.; NOGUEIRA, M.L.L. Políticas Educacionais e a Formação de Professores para a Educação Inclusiva no Brasil. Revista Integração, Brasília, v. 24, ano 14, p. 22-27, jan., 2002.

KAFROUNI, R.; PAN, M.A.G.S. A Inclusão de Alunos com Necessidades Educativas Especiais e os Impasses Frente à Capacitação dos Profissionais da Educação Básica: um estudo de caso. Revista InterAÇÃO, Curitiba, v. 5, p. 31-46, jan./dez., 2001.

LARROSA, J. Ensaio, diário e poema como variantes da autobiografia: a propósito de um "poema de formação" de Andrés Sánchez Robayna. In: SOUZA, E.C. de; ABRAHÃO, M.H.M.B. (Org.). Tempos, narrativas e ficções: a invenção de si. Porto Alegre: EDIPUCRS, 2006. p. 183-202.

MRECH, L. M.. Os desafios da educação especial, o plano nacional de educação e a universidade brasileira. Revista Brasileira de Educação Especial, Piracicaba, v. 3, n. 5, 127-146, setembro, 1999.

NAKAYAMA, B.C.M.S.; FIORENTINI, D.; BARBOSA, J.G. O potencial heurístico e autoformativo das biografias educativas para os formadores de professores de matemática. Ciências Humanas e Sociais em Revista. Seropédica, v. 32, n.2, p. 103-115, jul./dez., 2010.

PASSEGGI, M.C. A formação do formador na abordagem autobiográfica. A experiência dos memoriais de formação. In: SOUZA, E.C. de; ABRAHÃO, M.H. M.B. (Org.). Tempos, narrativas e ficções: a invenção de si. Porto Alegre: EDIPUCRS, 2006. p. 203-218. 
PASSEGGI, M.C. Narrar é humano! Autobiografar é um processo civilizatório. In: ; SILVA, V.B. (Org.). Invenções de vidas, compreensão de itinerários e alternativas de formação. São Paulo: Cultura Acadêmica, 2010. p. 103-130.

PRADO, G.V.T.; SOLIGO, R. Memorial de Formação: quando as memórias narram a história de formação.... In: . (Org.) Porque escrever é fazer história: revelações, subversões e superações. Campinas, SP: Editora Alínea, 2007. p. 45-59.

PRADO, G.V.T.; FERREIRA, C.R.; FERNANDES, C.H. Narrativa Pedagógica e Memoriais de Formação: Escrita dos Profissionais da Educação? Revista Teias, Rio de Janeiro, v. 12, n. 26, p. 143-153, set./dez., 2011.

ROSA, F.M.C. Professores de Matemática e a Educação Inclusiva: análises de memoriais de formação. 2013. 271f. Dissertação (Mestrado em Educação Matemática) - Instituto de Geociências e Ciências Exatas, Universidade Estadual Paulista, Rio Claro, 2013.

ROSA, E.A.C. Professores que ensinam matemática e a inclusão escolar: algumas apreensões. 2014. 160f. Dissertação (Mestrado em Educação Matemática) - Instituto de Geociências e Ciências Exatas, Universidade Estadual Paulista, Rio Claro, 2014.

SARTORI, A.T. Estilo em Memoriais de Formação. Revista da ABRALIN, São Carlos, v. 7, n. 2, p. 273 298, jul./dez. 2008.

SCHMIDT, L.M.; RIBAS, M.H.; CARVALHO, M.A. de. A prática pedagógica como fonte de conhecimento. Revista Olhar de Professor, Ponta Grossa, v.1, n. 1, p. 9-23, outubro, 1998.

SOUZA, E.C. de. A arte de contar e trocar experiências: reflexões teórico-metodológicas sobre história de vida em formação. Revista Educação em Questão, Natal, v. 25, n. 11, p. 22-39, jan./abr., 2006.

TARDIF, M. Saberes docentes e formação profissional. 11 ed. Petrópolis, RJ: Vozes, 2010.

TEIXEIRA, L.R.M. et al.. As narrativas de professores sobre a escola e a mediação de um Grupo de Pesquisa-Formação. Revista Formação Docente, Belo Horizonte, v. 03, n. 03, p. 121-135, ago./dez., 2010. 